\title{
Sarcoidosis pulmonar: lo típico y lo atípico
}

\author{
Pulmonary sarcoidosis: the typical and atypical
}

\author{
Adriana Morales-Cárdenas, MD ${ }^{1}$ María Carolina Pérez, MD² Jacqueline Mugnier, MD ${ }^{3}$ \\ Adriana BARRERA, MD ${ }^{4}$ AlejANDRo LÓPEZ, MD ${ }^{5}$
}

\section{Resumen}

La sarcoidosis es una enfermedad crónica y multisistémica de causa poco conocida, con un pico de incidencia entre los 20 y 29 años, con mayor prevalencia en el género femenino y en la raza negra. El órgano más frecuentemente afectado es el pulmón (90\%), que es sintomático solamente en el 50\%.

El diagnóstico requiere confirmación histopatológica, excepto en pacientes con la triada de Löfgren. El hallazgo histológico característico es la presencia de granulomas no caseificantes, con células gigantes multinucleadas.

Las manifestaciones radiológicas de la enfermedad pulmonar por sarcoidosis son amplias e incluyen manifestaciones típicas de compromiso ganglionar (adenomegalias hiliares bilaterales y paratraqueales derechas) y parenquimatoso (nódulos perilinfáticos, opacidades parahiliares bilaterales y cambios por fibrosis) y manifestaciones atípicas de compromiso ganglionar (adenomegalias unilaterales, asimétricas), parenquimatoso (sarcoidosis alveolar y masas pulmonares), enfermedad de vía aérea, pleural y otras (micetomas). El 30\% de los pacientes tiene compromiso extrapulmonar, más frecuentemente hepático (40\%-60\%).

El pronóstico de esta entidad es bueno, con una remisión en el $66 \%$ de los pacientes, y se basa en la clasificación de Scadding para la radiografía de tórax, aunque estudios en escanografía han demostrado que hallazgos como los nódulos centrilobulillares, la consolidación, el vidrio esmerilado y el engrosamiento de septos interlobulillares se correlacionan con reversibilidad de las alteraciones en imágenes.

Palabras clave: sarcoidosis; pulmonar; tomografía computarizada; radiología; fibrosis pulmonar.

\begin{abstract}
Sarcoidosis is a chronic multisystemic disease whose cause is not well understood. Peak incidence occurs among people between 20 and 29 years of age, and the disease has higher prevalences among women and black people than in the general population. The lungs are the most frequently affected organ, accounting for $90 \%$ of cases, but only $50 \%$ are symptomatic.

Diagnosis requires histopathological confirmation, except in patients who have the Löfgren triad. Characteristic histology consists of noncaseating granulomas with giant multinucleated cells.

Radiological manifestations of pulmonary disease due to sarcoidosis are extensive. They include typical lymphadenopathy, especially bilateral hilar lymphadenopathy, and right paratracheal lymphadenopathy; parenchymal manifestations including perilymphatic nodules, bilateral perihilar opacities, and changes due to fibrosis; atypical lymphadenopathy including unilateral lymphadenopathy and asymmetric lymphadenopathy; and parenchymal manifestations including alveolar sarcoidosis, lung masses, airway diseases, pleurisy and other manifestations such as mycetoma. Thirty percent of patients have extrapulmonary involvement, most frequently hepatic $(40 \%-60 \%)$.

The prognoses for patients with this disease is good, and remission occurs in $66 \%$ of patients. The Scadding criteria for chest $\mathrm{x}$-rays is currently used to stage sarcoidosis, but CT scan studies have shown findings such as centrilobular nodules, consolidation, ground glass patterns and thickening of interlobular septa that correlate with reversibility of imaging alterations.
\end{abstract}

Keywords: sarcoidosis, pulmonary, computed tomography, radiology, pulmonary fibrosis
${ }^{1}$ Residente de Radiología, Universidad del Rosario. Departamento de Radiología, Fundación CardioInfantil, Instituto de Cardiología. Bogotá, Colombia.

${ }^{2}$ Radióloga, Departamento de Radiología, Fundación CardioInfantil, Instituto de Cardiología. Bogotá, Colombia.

${ }^{3}$ Patóloga, Departamento de Patología, Fundación CardioInfantil, Instituto de Cardiología. Bogotá, Colombia.

Autor de correspondencia

Adriana Morales Cárdenas. Calle 140 Bis \# 14A-29, Bogotá. Tel.: +57 (320)576.25.31. Correo electrónico: asmoralesca@gmail.com.

Recibido: 20/08/17. Aceptado: 20/11/17. 


\section{Introducción}

La sarcoidosis es una enfermedad crónica y multisistémica caracterizada por la presencia de granulomas de células epitelioides no caseificantes que pueden afectar cualquier órgano, siendo el pulmón el más frecuente $(90 \%)(1)$.

El diagnóstico se basa en la sospecha clínica con imágenes diagnósticas y estudio histopatológico compatible. En este sentido, la adecuada evaluación radiológica es crucial, ya que determina la extensión de la enfermedad y permite un seguimiento objetivo (2).

Teniendo en cuenta lo anterior, a continuación, se discutirán detalladamente los hallazgos radiológicos, en tomografía de alta resolución, del órgano blanco afectado con mayor frecuencia (pulmón), ya que, aunque el método estándar donde se escribieron las alteraciones radiológicas inicialmente es la radiografía, la tomografía de alta resolución provee un mayor detalle con mejores características operativas $(3,4)$.

\section{Marco teórico}

\section{Epidemiología}

El pico de incidencia se encuentra en la tercera década de la vida (20-29 años), con una predilección por el género femenino y raza negra (Figura 1) (2). La prevalencia es variable, siendo la raza el principal factor de variabilidad. En Estados Unidos, la prevalencia es de 3/100 000 habitantes en la población blanca, mientras que en la población afroamericana aumenta a 47/100 000 (5).

\section{Manifestaciones clínicas}

El 50\% de los pacientes es sintomático; de esto, los síntomas más frecuentes son el respiratorio (tos, disnea, hiperreactividad bronquial) y cutáneo (eritema nodoso), además de la fatiga y pérdida de peso (2). El compromiso de las glándulas salivales es raro; sin embargo, se hace frecuente en pacientes mayores de 70 años (6).

La tríada clásica de la sarcoidosis (Lofgren) se describe como la presencia de manifestaciones clínicas

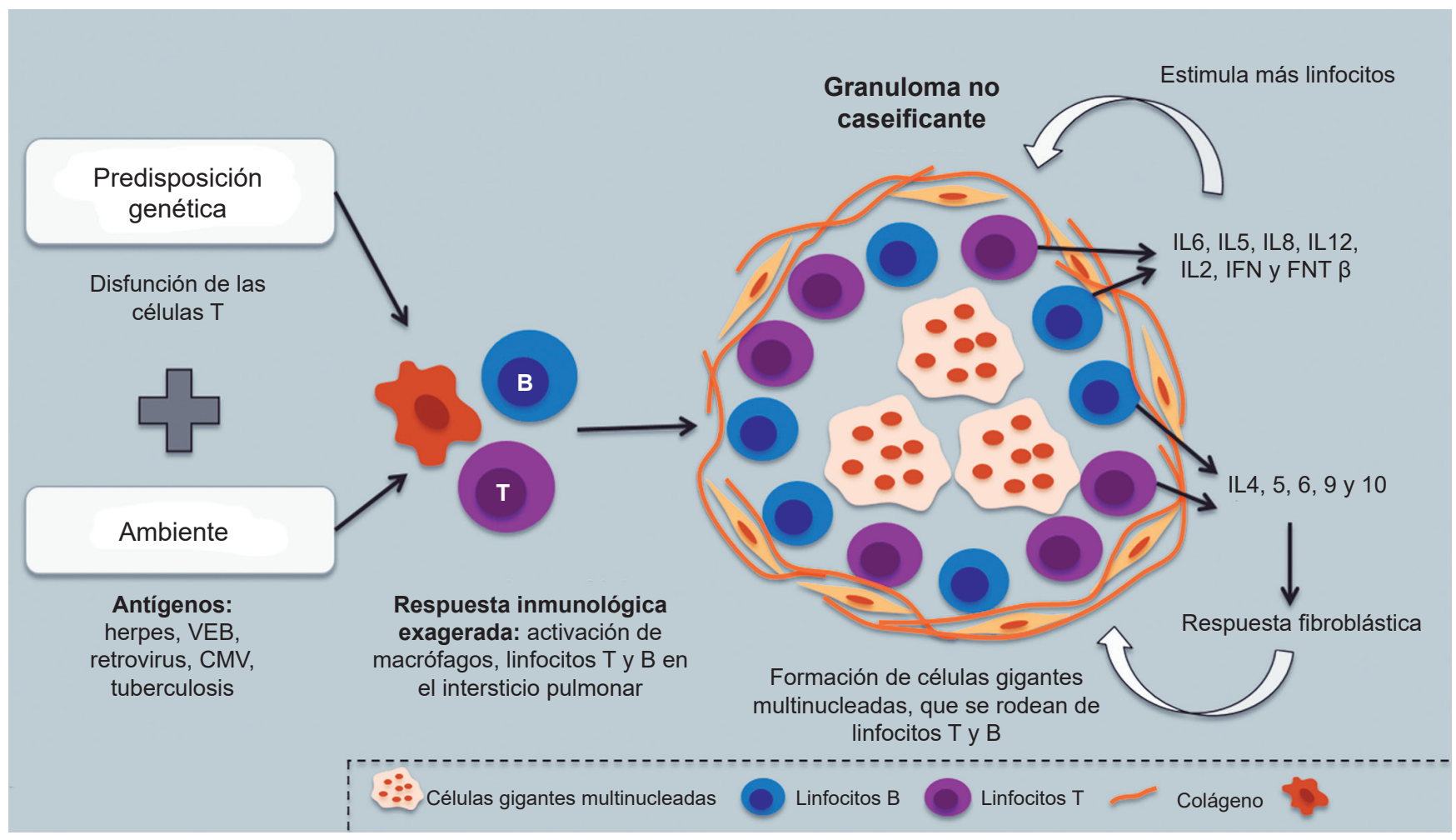

Figura 1. Esquema de la fisiopatología de la sarcoidosis. CMV: citomegalovirus; FNT $\beta$ : factor de necrosis tumoral beta; IFN: interferón; IL: interleucina; VEB: virus de Epstein-Barr. 
que incluyen eritema nodoso y artritis asociadas con adenomegalias intratorácicas. En estos casos no es necesario la confirmación histopatológica (7).

\section{Fisiopatología}

La fisiopatología de esta enfermedad es desconocida. Se cree que existen agentes gatillo-infecciosos (virales, micobacterias u hongos) o exposicionales, que inducen una respuesta inflamatoria en personas genéticamente susceptibles, esto lleva a la formación de granulomas en cualquier órgano (Figura 1). Histológicamente, estos granulomas se forman de células gigantes multinucleadas centrales y linfocitos, fibroblastos y colágeno en la periferia y, en raras ocasiones, presentan necrosis coagulativa focal (6).

\section{Diagnóstico}

Se necesita la confirmación histopatológica y exclusión de otras enfermedades con hallazgos histopatológicos similares, excepto en los pacientes que se presenten con tríada de Lofgren (7).

Dado el compromiso difuso del intersticio pulmonar en la sarcoidosis, la biopsia transbronquial tiene un alto rendimiento $(79 \%)$, con bajo índice de complicaciones $(1,44 \%)$ (8). Idealmente, esta se debe realizar en los segmentos donde se identifiquen alteraciones tomográficas $(2,9)$.

En el lavado broncoalveolar existe un cociente de linfocitos CD4/CD8 mayor de 3,5; con una especificidad del 93\%-96\% para el diagnóstico. En los casos en que se documente esta disociación se considera altamente probable el diagnóstico de sarcoidosis y no se necesitaría la confirmación con biopsia (10).

Las pruebas de función pulmonar muestran un patrón restrictivo con disminución de los volúmenes y capacidad de difusión del monóxido de carbono. El patrón obstructivo es menos frecuente $(5,7 \%)$ y se asocia con un estadio 4 en los hallazgos radiológicos, así como mayor morbimortalidad (2).

\section{Histopatología}

Histológicamente, esta enfermedad se caracteriza por la presencia de granulomas no caseificantes con un centro de histiocitos epiteloides y células gigantes multinucleadas, que pueden contener cuerpos asteroides, de Schaumanny, cristales de oxalato y carbonato de calcio, rodeados por linfocitos, fibroblastos y colágeno (Figura 2). Ocasionalmente puede existir necrosis focal de coagulación (2).
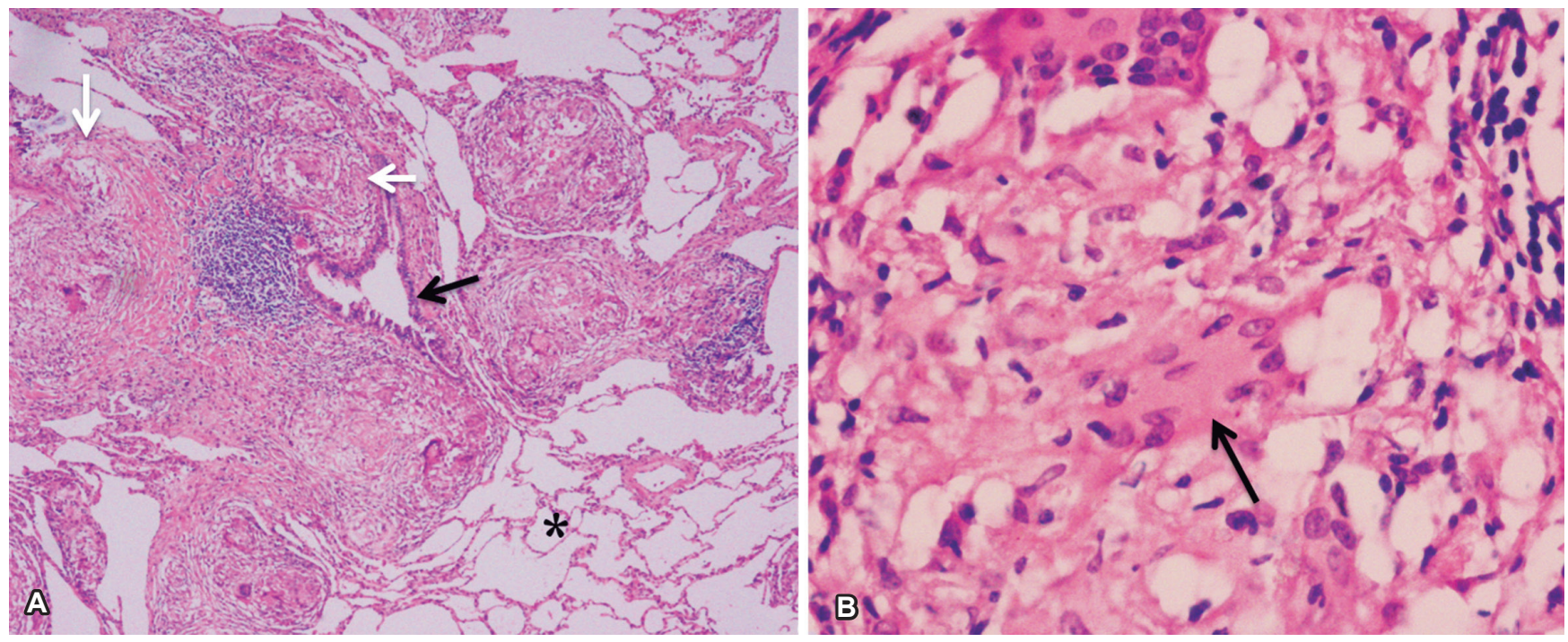

Figura 2. Tinciones de hematoxilina/eosina $4 X(A)$ y $40 X(B)$ de biopsia pulmonar, donde se identifican alvéolos normales (asterisco negro), pared de un bronquiolo (flecha negra) con infiltrado inflamatorio crónico y presencia de múltiples granulomas no caseificantes (fechas blancas) constituidos por células epiteloides y células gigantes multinucleadas. 
En el pulmón, estos granulomas tienen distribución perilinfática en relación con el intersticio peribroncovascular, subpleural, interlobulillar e intralobulillar (2).

\section{Manifestaciones radiológicas de la enfermedad pulmonar}

Durante la historia natural de la enfermedad, el 90\% de los pacientes desarrollará enfermedad pulmonar, con un alto impacto en la morbimortalidad (11). El estudio de elección para el diagnóstico es la tomografía computarizada de alta resolución (TCAR) en corte axial, por su alta sensibilidad para la detección de adenopatías y compromiso parenquimatoso temprano aunque en 1999 el consenso de ATS/ERS/WASOG (American Thoracic Society/European Respiratory Society/World Association for Sarcoidosis and Other Granulomatous Disorders) estipuló que las indicaciones de tomografía son hallazgos clínicos y/o en la radiografía de tórax atípicos, sospecha clínica con radiografía de tórax normal y cuando se sospechan complicaciones $(2,12)$.

Las manifestaciones radiológicas típicas de la sarcoidosis pulmonar incluyen: adenomegalias hiliares y enfermedad intersticial (micronódulos de distribución perilinfática, cambios fibróticos y opacidades parahiliares bilaterales). Se han descrito manifestaciones atípicas, como opacidades alveolares, masas cavitadas, patrón miliar, mosaico de atenuación, compromiso de la vía aérea y enfermedad pleural (Tabla 1).

Los hallazgos en la radiografía de tórax se clasificaron por Scadding en 4 estadios, los cuales se correlacionan con el pronóstico de los pacientes (Tabla 2) $(13,14)$. Sin embargo, dada la baja sensibilidad de la radiografía para detectar adenopatías (descubre del 50\%-60\% de las adenopatías visualizadas en tomografía) y el compromiso pulmonar (detecta del 30\%-40\% de la afección parenquimatosa observada en tomografía), la tomografía computarizada de alta resolución es el estudio de lección (6).

\section{Adenomegalias hiliares y mediastinales}

\section{Típicas}

Es la manifestación más frecuente (75\%-90\%) con adenopatías hiliares simétricas y paratraqueales derechas (tríada de Garland) (Figura 3), y menos frecuente en las estaciones paratraqueales izquierdas, subcarinales y en la ventana aortopulmonar $(2,11)$.

Tabla 1. Hallazgos típicos y atípicos en la tomografía de tórax del compromiso pulmonar por sarcoidosis

\begin{tabular}{|c|c|c|}
\hline Enfermedad pulmonar & Hallazgos típicos & Hallazgos atípicos \\
\hline Ganglionar & $\begin{array}{l}\text { Adenomegalias hiliares bilaterales simétricas } \\
\text { y paratraqueales derechas }\end{array}$ & Adenomegalias unilaterales, asimétricas \\
\hline Parénquima & $\begin{array}{l}\text { Nódulos perilinfáticos. } \\
\text { Opacidades parahiliares bilaterales } \\
\text { Cambios por fibrosis: opacidades reticulares, } \\
\text { distorsión de la arquitectura pulmonar, } \\
\text { bronquiectasias de tracción, pérdida de } \\
\text { volumen de los lóbulos superiores, panal de } \\
\text { abejas, quistes, enfisema paracicatrizal }\end{array}$ & $\begin{array}{l}\text { Sarcoidosis alveolar: áreas de consolidación y/o } \\
\text { vidrio esmerilado } \\
\text { Nódulos pulmonares y masas }\end{array}$ \\
\hline Vía aérea & $(-)$ & $\begin{array}{l}\text { Enfermedad de la vía aérea pequeña: mosaico } \\
\text { de atenuación por atrapamiento aéreo } \\
\text { Enfermedad de la vía aérea central: } \\
\text { engrosamiento liso o irregular de la pared de la } \\
\text { tráquea y/o bronquios, estenosis por compresión } \\
\text { extrínseca y atelectasias secundarias }\end{array}$ \\
\hline Pleura & $(-)$ & $\begin{array}{l}\text { Derrame pleural } \\
\text { Neumotórax } \\
\text { Quilotórax } \\
\text { Engrosamiento pleural }\end{array}$ \\
\hline Otras & & Micetoma \\
\hline
\end{tabular}


Tabla 2. Clasificación de Scadding

\begin{tabular}{|c|c|c|c|c|}
\hline Estadio & Hallazgos & $\begin{array}{l}\text { Porcentaje en el momento del } \\
\text { diagnóstico }\end{array}$ & $\begin{array}{l}\text { Remisión } \\
\text { espontánea }\end{array}$ & Esquema \\
\hline 0 & Sin alteraciones & $5 \%-10 \%$ & $90 \%-100 \%$ & \\
\hline 1 & Linfadenopatía & $50 \%$ & $60 \%-90 \%$ & \\
\hline 2 & $\begin{array}{l}\text { Linfadenopatía e infiltrados } \\
\text { pulmonares }\end{array}$ & $25 \%-30 \%$ & $40 \%-70 \%$ & \\
\hline 3 & Infiltrados pulmonares & $10 \%-12 \%$ & $10 \%-20 \%$ & \\
\hline 4 & Fibrosis pulmonar & $5 \%$ & $0 \%$ & \\
\hline
\end{tabular}

A los 10 años del diagnóstico, 20\% de los pacientes presenta calcificaciones en los ganglios, las cuales pueden ser centrales, amorfos, en forma de palomita de maíz o en cáscara de huevo (Figura 3) (11). Los primeros 5 años después del diagnóstico solo $3 \%$ manifiesta calcificaciones ganglionares (15).

\section{Atípicas}

La presentación atípica de las adenomegalias incluye compromiso unilateral o asimétrico (1\%-3\%) (Figura 4) o localización en estaciones ganglionares inusuales (mediastinales anteriores y posteriores, mamaria interna, paravertebrales o retrocrurales) (11). 

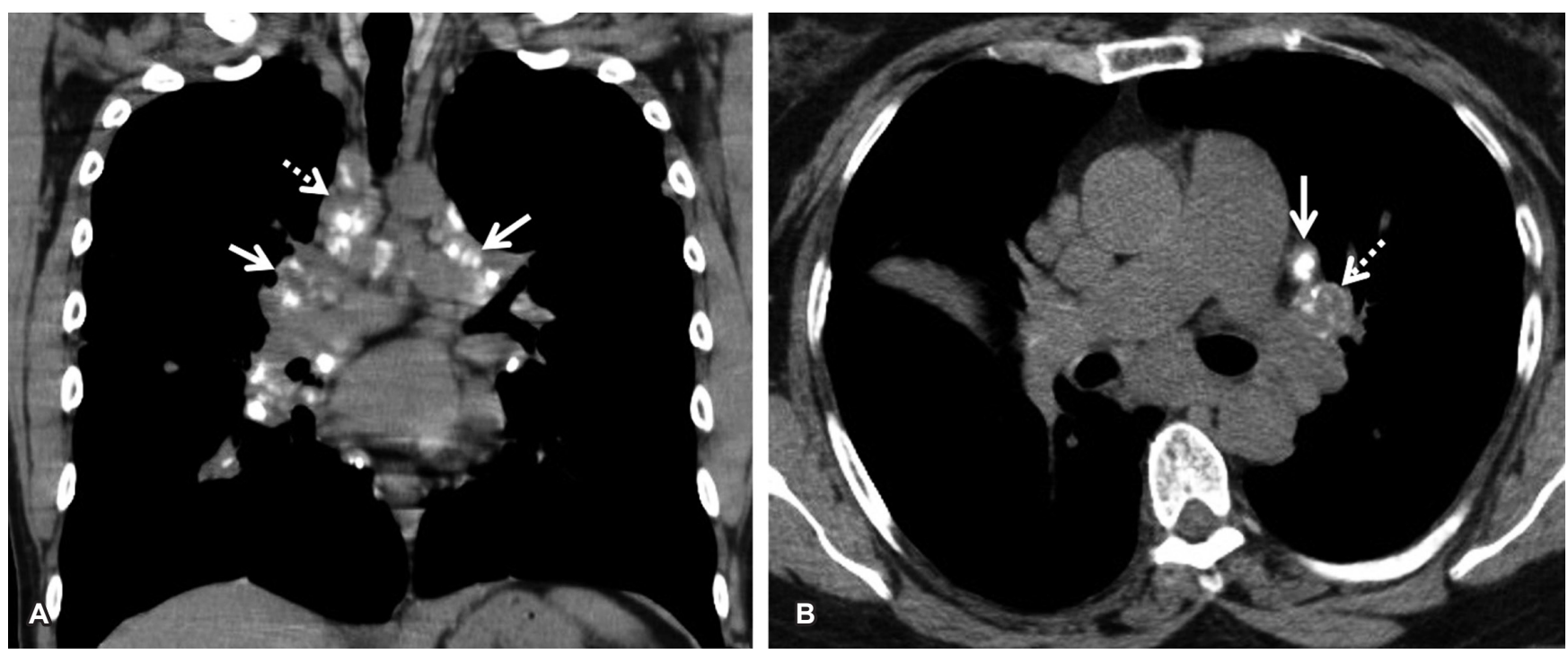

Figura 3. TCAR en reconstrucción coronal y corte axial de un paciente con sarcoidosis. Se evidencia la localización típica de las adenomegalias en la triada de Garland. A. Paratraqueal derecha (flecha discontinua) y parahiliar bilateral (flecha) con calcificaciones amorfas. B. Patrones de calcificación en palomita de maíz (flecha discontinua) y central (flecha).

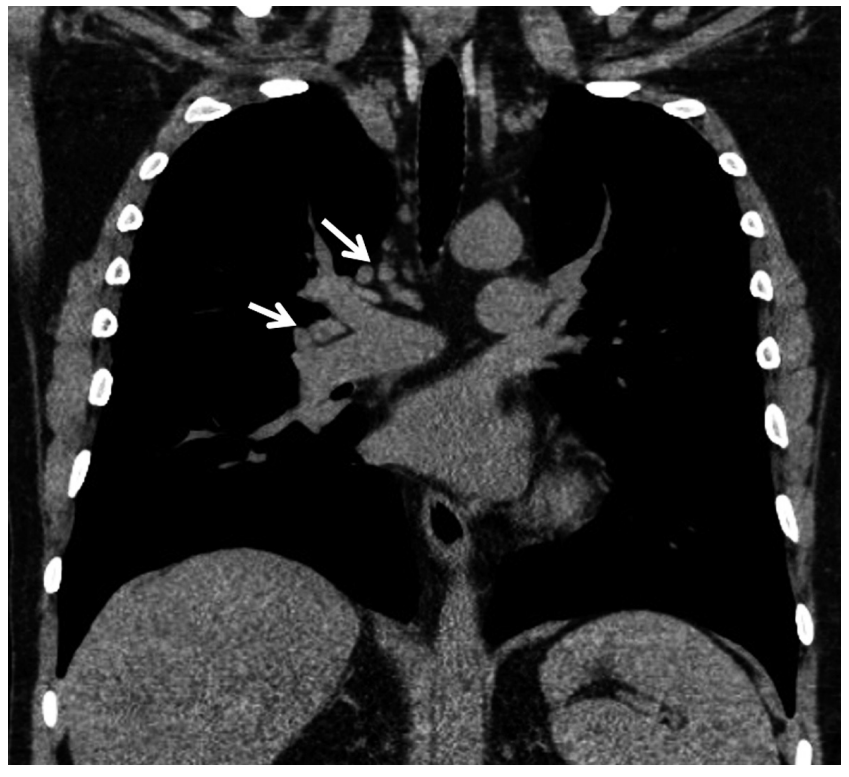

Figura 4. TCAR en reconstrucción coronal de un paciente con sarcoidosis y compromiso ganglionar asimétrico. Se evidencia aumento en el número de ganglios de localización paratraqueal e hiliar derechas (flechas).

En este caso es importante considerar otros diagnósticos diferenciales, como tuberculosis, histoplasmosis, linfoma y enfermedad metastásica $(2,11)$.

\section{Enfermedad parenquimatosa}

Es la segunda manifestación más frecuente $(25 \%$ $50 \%)(11,16)$.

\section{Típica}

Los hallazgos típicos en el parénquima pulmonar incluyen nódulos perilinfáticos, cambios por fibrosis y opacidades parahiliares.

Los nódulos perilinfáticos son pequeños ( 2 a $4 \mathrm{~mm}$ ), redondeados, bien definidos y distribuidos simétricamente en ambos pulmones, con predilección por los lóbulos superiores (segmentos posteriores y apicales) y tercio medio de los hemitórax. En TCAR, el 100\% de los pacientes con enfermedad parenquimatosa presenta nódulos perilinfáticos (Figura 5) (11).

La distribución perilinfática en el pulmón incluye el intersticio peribroncovascular, intersticio subpleural (incluidas las cisuras), los septos interlobulillares y regiones centrilobulillares (11).

Cuando múltiples nódulos se encuentran cercanos, sin coalescer, distribuidos a lo largo de los vasos linfáticos, predominantemente periféricos en los tercios superior y medio de ambos pulmones, configura el sig- 

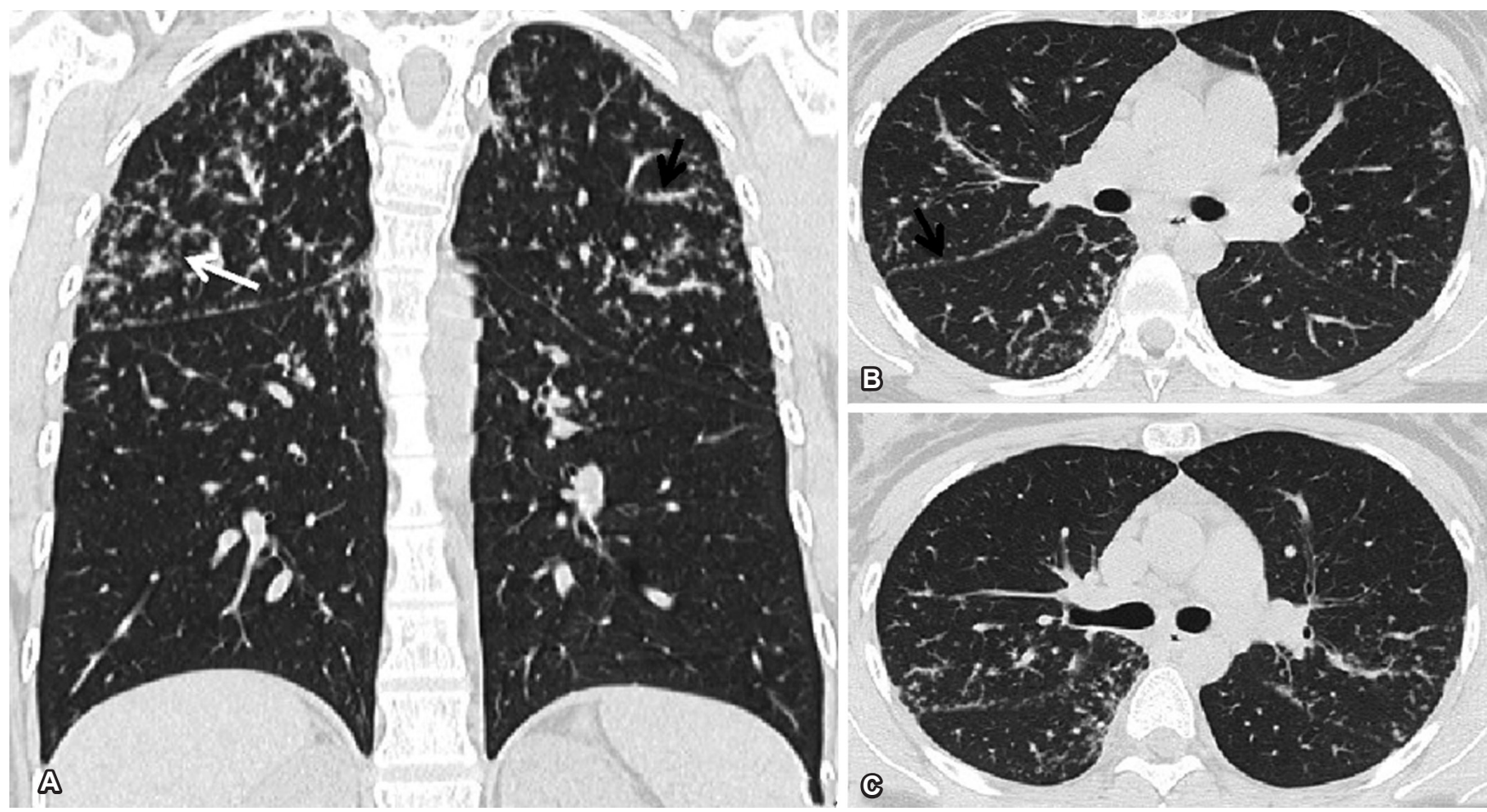

Figura 5. TCAR en reconstrucción coronal $(\mathbf{A})$ y cortes axiales $(\mathbf{B}$ y $\mathbf{C})$ de un paciente con sarcoidosis, en la que se identifican nódulos de distribución perilinfática en el intersticio peribroncovascular y subpleural (flechas negras) con el signo del cúmulo sarcoide (flecha blanca).

no del cúmulo sarcoideo, el cual se describió recientemente (Figura 5) $(2,6)$.

El diagnóstico diferencial de los nódulos de distribución linfática incluye la carcinomatosis linfangítica, enfermedad linfoproliferativa, silicosis y amiloidosis
(11). El 50\% de los pacientes presenta engrosamiento de los septos inter e intralobulillares, predominantemente en los tercios superior y medio de los pulmones (Figura 6). El diagnóstico diferencial más importante de estos cambios es la carcinomatosis linfangítica.
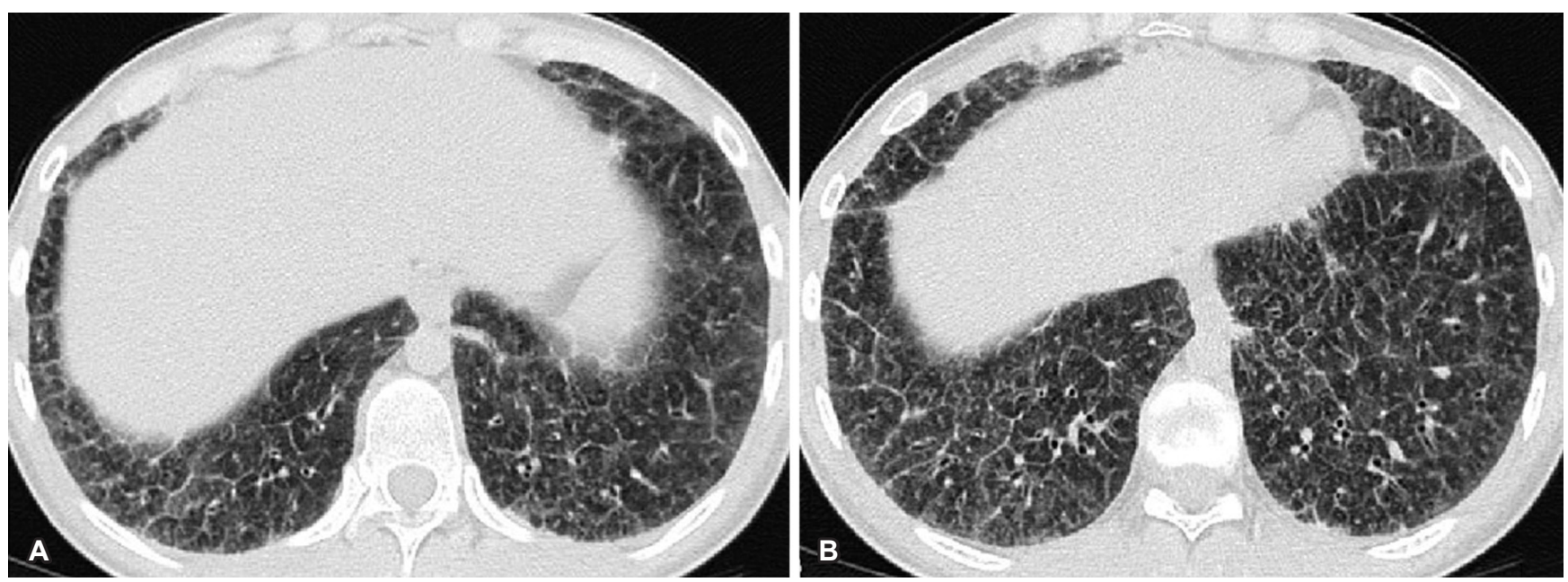

Figura 6. TCAR en cortes axiales de una paciente con sarcoidosis que se manifestó con engrosamiento nodular de los septos inter e intralobulillares (A y $\mathbf{B})$ de ambos pulmones. 
En los casos de fibrosis pulmonar (10\%-30\%), los hallazgos incluyen opacidades lineales reticulares; panal de abejas; bulas; enfisema paracicatrizal; bronquiectasias de tracción y distorsión de la arquitectura pulmonar, predominantemente en los lóbulos superiores; y pérdida de volumen de los lóbulos superiores (desplazamiento posterior de los bronquios fuentes y de los bronquios lobares superiores) (Figura 7) $(2,11)$.

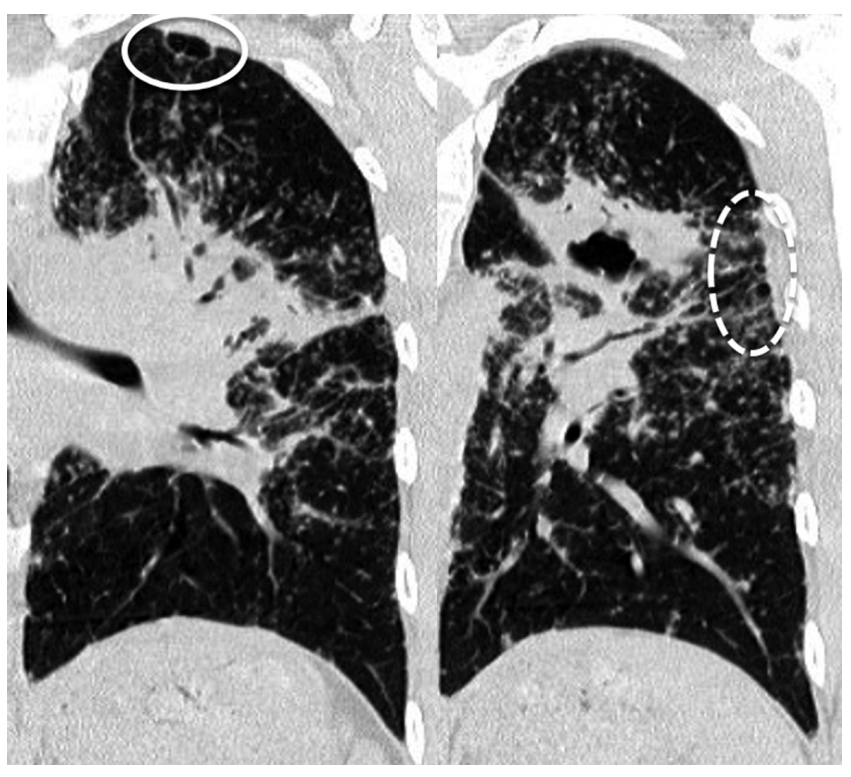

Figura 7. TCAR en reconstrucción coronal de un paciente con sarcoidosis y fibrosis pulmonar secundaria, con formación de quistes (circulo continuo), enfisema paracicatrizal (circulo discontinuo) y distorsión de la arquitectura pulmonar.

Las opacidades parahiliares suelen ser confluentes, bilaterales e irradiadas del hilio a la periferia (Figura 8) (2).

\section{Atípicas}

Algunas de las manifestaciones atípicas en el parénquima pulmonar son los nódulos grandes y masas, que representan granulomas intersticiales coalescentes de localización parahiliar y periférica (Figura 9A). Ocasionalmente pueden tener broncograma aéreo, cavitación $(<3 \%$ de los pacientes con enfermedad parenquimatosa) y signo del halo o halo invertido, este último por la presencia de nódulos menos densos y coalescentes a nivel central $(17,18)$. En la periferia de las masas o nódulos puede haber nódulos satélites de menor ta- maño, configurando el signo de galaxia (Figura 9B), el cual también se describe en pacientes con tuberculosis $(9 \%)(15,19)$.

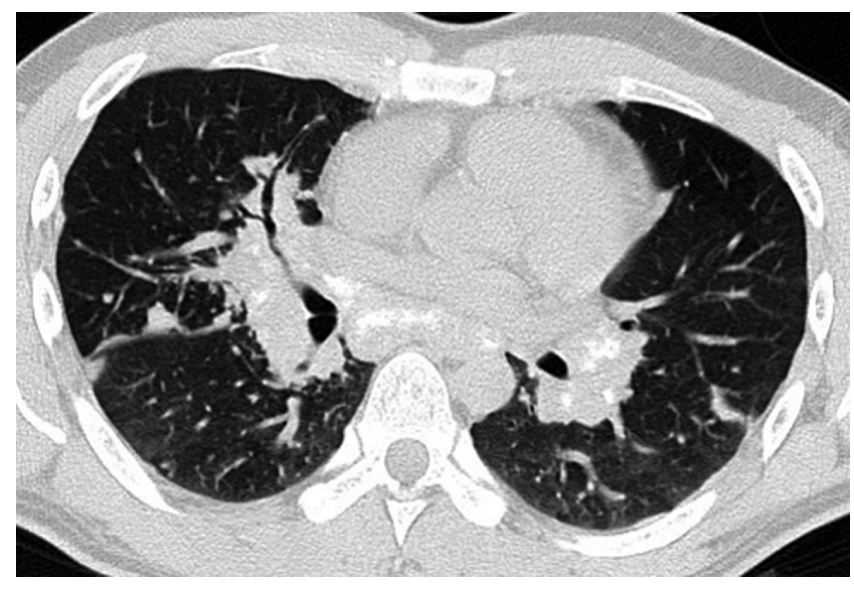

Figura 8. Corte axial de TCAR de un paciente con sarcoidosis que se manifestó con opacidades parahiliares bilaterales, confluentes y con broncograma aéreo.

En el diagnóstico diferencial de estas lesiones se debe incluir silicosis, beriliosis, tuberculosis y talcosis.

Entre $10 \%$ y $20 \%$ de los pacientes presenta consolidación del espacio aéreo. Usualmente esta es bilateral, simétrica, de bordes mal definidos, con broncograma aéreo y, en pocos casos, con signo del halo, que representa granulomas y macrófagos intraalveolares sobreagregados (20). Esta presentación se informó por primera vez por Marten y colaboradores, que describieron la distribución periférica no segmentaria, de localización en los tercios medios y superior de ambos hemitórax, con respeto de los ángulos costofrénicos (21). Este patrón se denomina forma acinar o alveolar de la sarcoidosis, que puede simular una neumonía, tuberculosis o neumonía de organización (Figura 10) $(2,11,22)$.

Otros hallazgos frecuentes son las opacidades en vidrio esmerilado, resultado de la confluencia de micronódulos no visibles a la resolución de la TCAR y por lesiones intersticiales fibróticas que causan compresión o atelectasia parcial de los alveolos. Generalmente se asocia con nódulos intersticiales $(11,23)$.

En casos raros, la sarcoidosis puede presentarse de forma cavitaria $(<0,8 \%)$. Esta forma es más frecuen- 

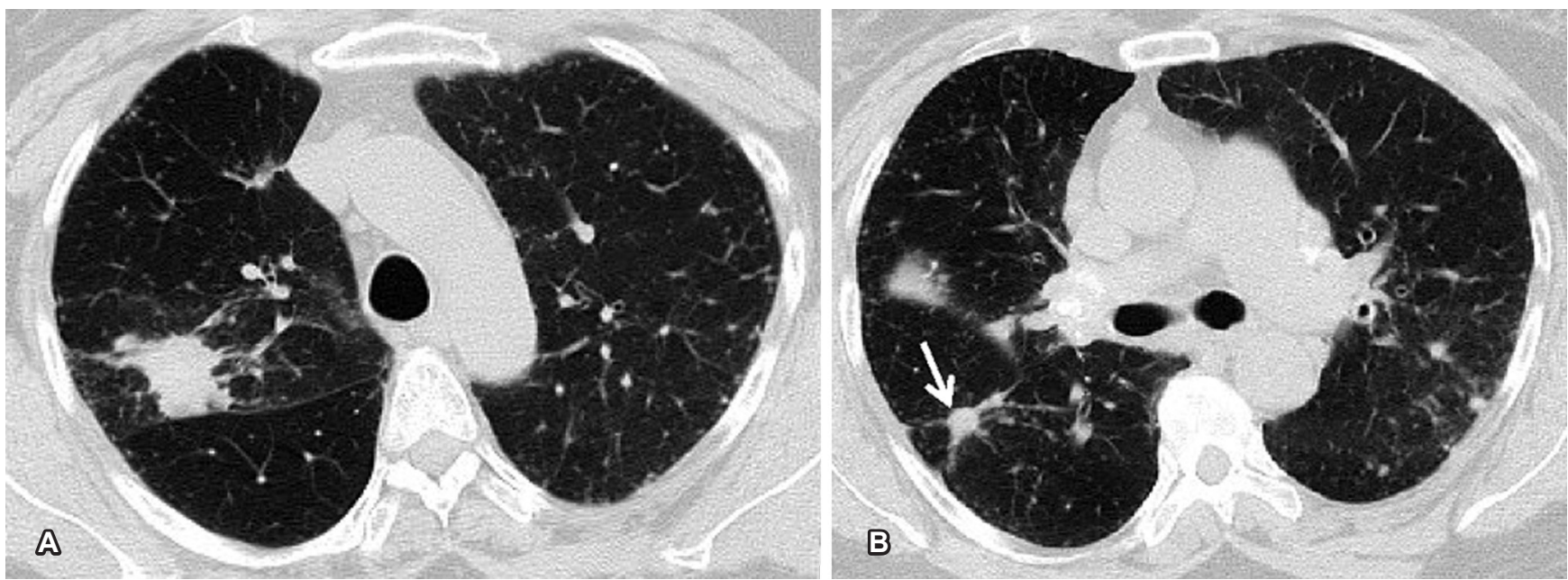

Figura 9. Corte axial de TCAR de pacientes con presentación atípica de compromiso parenquimatoso pulmonar y presencia de una masa con densidad de tejidos blandos en el lóbulo superior derecho, así como micronódulos de distribución perilinfática (A) y un nódulo con densidad de tejidos blandos con el signo de galaxia (B).
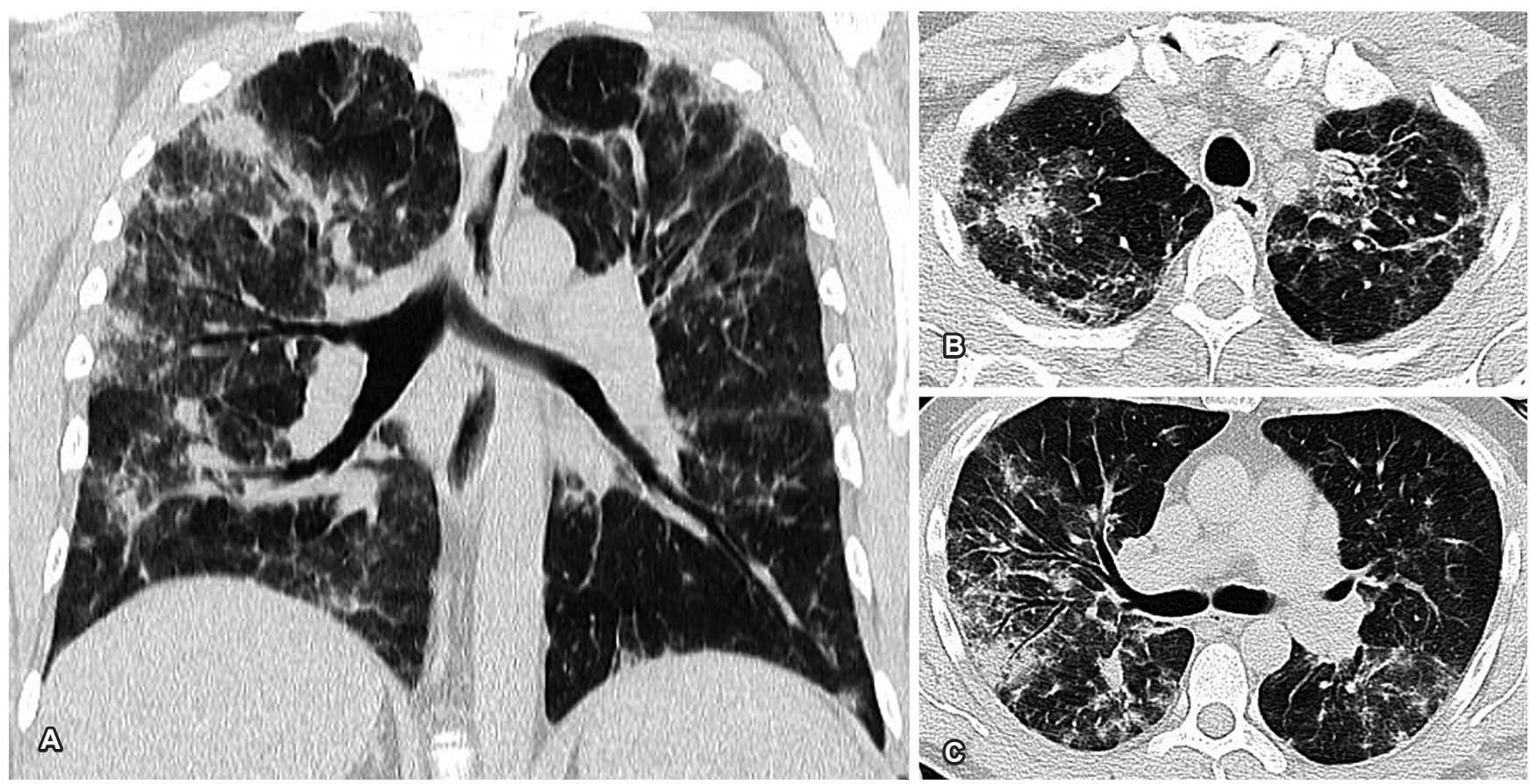

Figura 10. TCAR en reconstrucción coronal (A) y cortes axiales (B y C) de un paciente con sarcoidosis alveolar. En las imágenes se evidencian múltiples parches de opacidades alveolares distribuidas predominantemente en lóbulos superiores y tercio medio de ambos pulmones asociados con opacidades en vidrio esmerilado.

te en pacientes jóvenes, y se atribuye a una angeítis sarcoide cavitaria. Estas cavidades pueden ser únicas, múltiples y de paredes delgadas o gruesas (11). Su evolución es impredecible y son frecuentes las com- plicaciones, como la formación de micetomas (Figura 11) (24). El diagnóstico diferencial más importante de esta presentación es la fibrosis masiva progresiva en pacientes con neumoconiosis (15). 

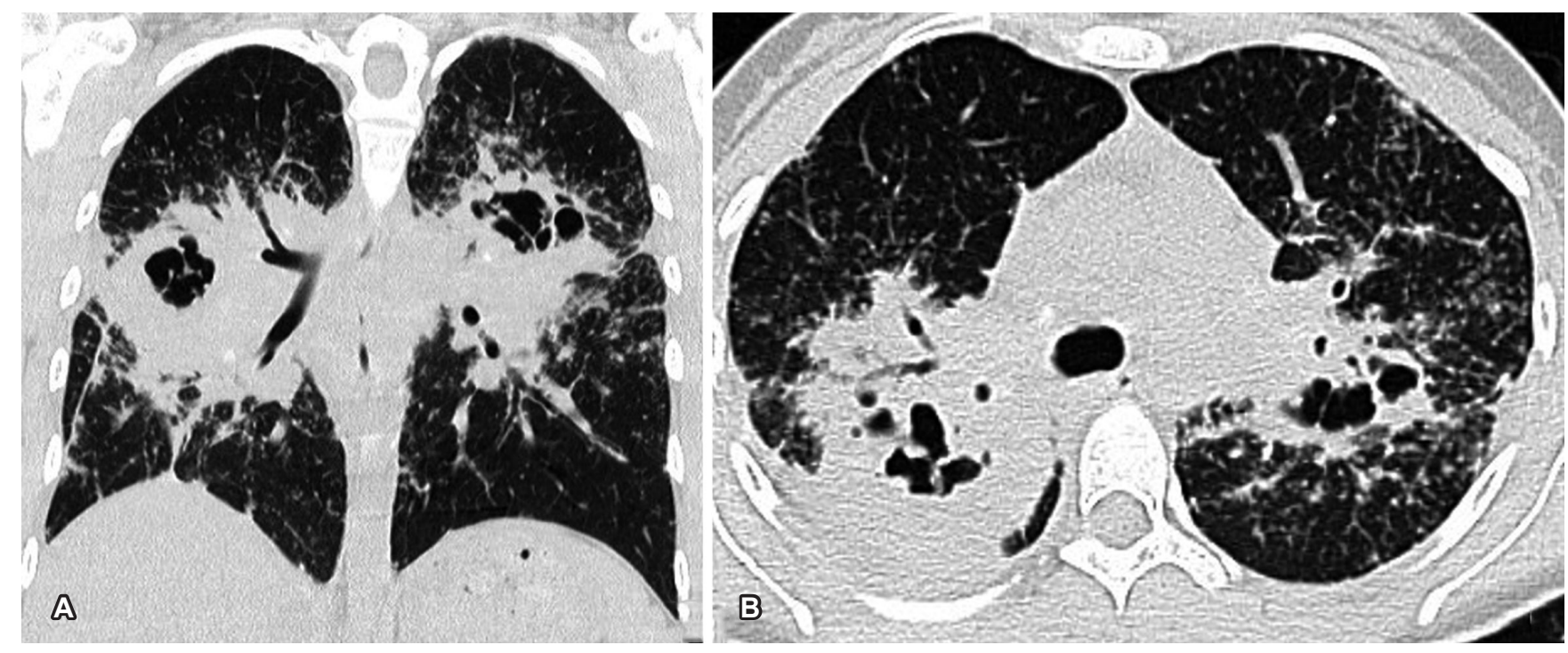

Figura 11. TCAR en reconstrucción coronal y corte axial de un paciente con sarcoidosis avanzada, en forma cavitaria, donde se identifican opacidades alveolares parahiliares bilaterales con signos de cavitación central asociadas con nódulos de distribución perilinfática.

Una complicación de las bulas y quistes característicos del estadio 4 de la sarcoidosis es la formación de los micetomas, con una frecuencia entre $1 \%$ a $3 \%$ (11). Estos se presentan con mayor frecuencia en pacientes con terapia inmunomoduladora con esteroides o metotrexato $(3,25)$.

Otra de las manifestaciones atípicas de la enfermedad parenquimatosa pulmonar es el patrón miliar $(<1 \%)$ formado por nódulos de distribución aleatoria. Este patrón es más frecuente en otras entidades, como la tuberculosis, neumoconiosis, metástasis, histoplasmosis, histiocitosis de células de Langerhans, entre otras (11).

\section{Otras manifestaciones atípicas}

\section{Hipertensión pulmonar}

La hipertensión pulmonar es rara en la sarcoidosis, con una prevalencia menor del 5\%. Los signos de hipertensión pulmonar en tomografía son:

- Aumento en el diámetro del tronco principal de la arteria pulmonar (>29 mm)

- Pérdida de la relación arteria bronquio
- Pérdida de la relación entre el tronco principal de la arteria pulmonar y la aorta $(>1)$.

Usualmente, la hipertensión pulmonar se desarrolla en pacientes con estadios avanzados de la enfermedad (fase fibrótica); sin embargo, se han descrito otros mecanismos causales, como la compresión extrínseca de las arterias pulmonares por adenomegalias (26). En algunos casos se ha escrito un compromiso venoso con un patrón de enfermedad venooclusiva pulmonar secundaria a la obstrucción de las venas de los septos interlobulillares por fibrosis perivascular o granulomas en las paredes vasculares; esta última se debe sospechar en pacientes con hipertensión pulmonar no asociada con fibrosis y engrosamiento irregular de los septos interlobulillares (27-29). La fibrosis pulmonar puede llevar al desarrollo de hipertensión pulmonar y falla cardíaca derecha (30).

\section{Enfermedad de la vía aérea}

La manifestación imagenológica más frecuente de la enfermedad de la vía aérea pequeña es el mosaico de atenuación por atrapamiento aéreo y de la enfermedad de la vía aérea central. Estas son las anormalidades traqueobronquiales, como la estenosis por inflamación 
granulomatosa de la pared bronquial o secundaria a compresión extrínseca por adenomegalias con atelectasias subyacentes o bronquiectasias en estadios finales de la enfermedad (Figura 12) $(2,11,29,31)$.

El mosaico de atenuación tiene diferentes causas, entre las que se encuentran la enfermedad intersticial de vía aérea pequeña o vascular. En sarcoidosis, la causa más frecuente es la enfermedad de la vía aérea pequeña por la obstrucción generada por los granulomas (2).
Las anormalidades traqueobronquiales incluyen estenosis por presencia de granulomas endobronquiales, que se puede manifestar como un engrosamiento liso, irregular o nodular de las paredes, o por compresión extrínseca por adenomegalias, lo cual puede generar atelectasias o bronquiectasias posobstructivas $(6,32)$. La enfermedad de la vía aérea se asocia con aumento en la morbilidad, mayores síntomas respiratorios y mortalidad en pacientes con sarcoidosis (33).
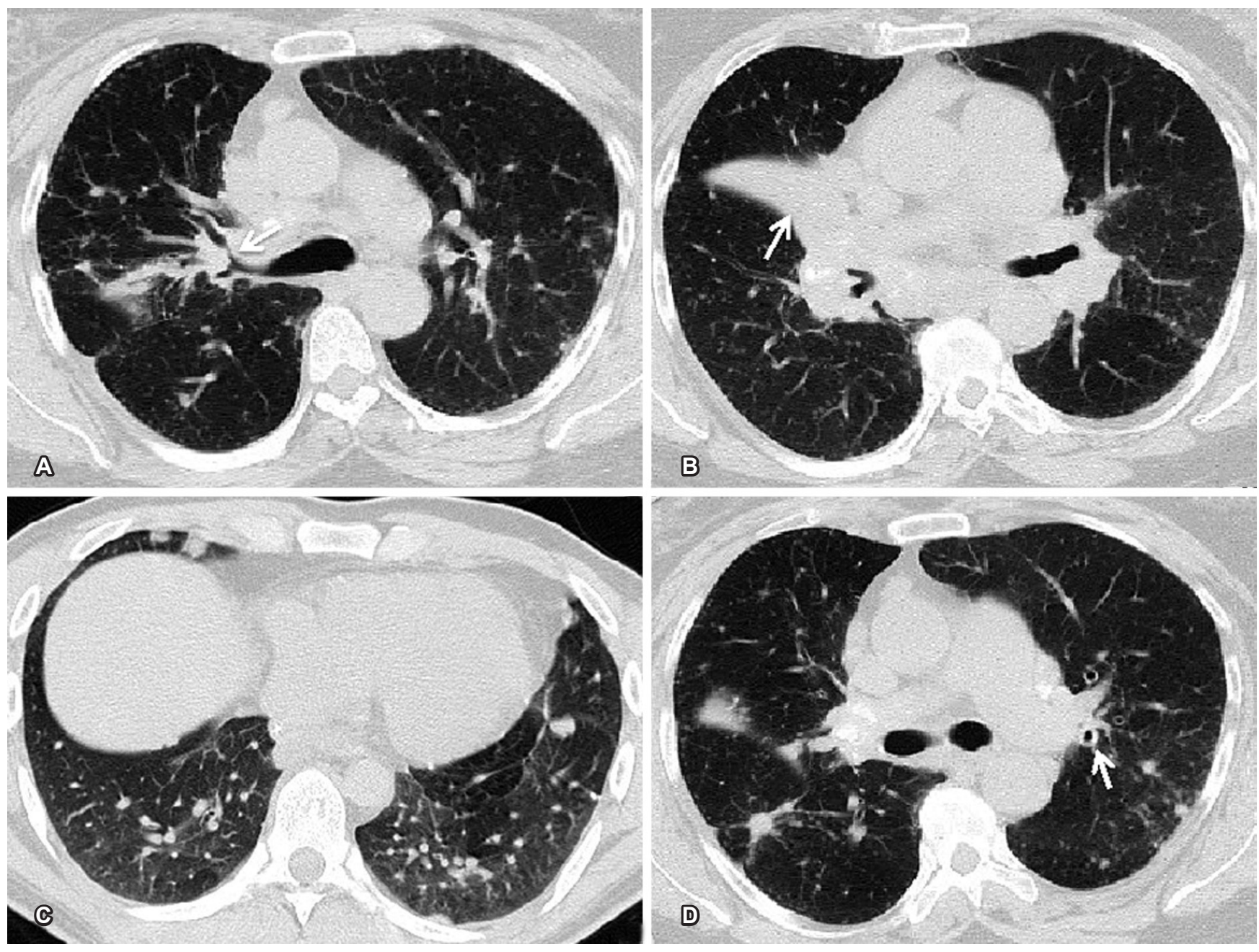

Figura 12. Cortes axiales de TCAR, donde se evidencia la compresión extrínseca del bronquio intermediario por una adenomegalia (A) con atelectasia secundaria del lóbulo medio (B, flecha blanca), con mosaico de atenuación en los cortes en espiración (C) por atrapamiento aéreo y engrosamiento de las paredes bronquiales ( $\mathbf{D}$, flecha blanca). Además de la enfermedad de la vía aérea, también se identifican micronódulos perilinfáticos ( $\mathbf{A}$ y $\mathbf{B}$ ) y nódulos subpleurales de mayor tamaño (C y $\mathbf{D})$. 


\section{Enfermedad pleural}

La enfermedad pleural ocurre en $1 \%$ a $4 \%$ de los pacientes (11). La manifestación más frecuente es derrame pleural, ya sea seroso (Figura 13), hemorrágico o quiloso.

Otras manifestaciones pleurales de la sarcoidosis incluyen neumotórax (2\%-3\%), secundario a la ruptura de quistes o bulas subpleurales, principalmente en pacientes con sarcoidosis en fase fibrótica, engrosamiento pleural y placas pleurales; estos últimos con predilección por los lóbulos inferiores $(11,34)$.

\section{Pronóstico y actividad de acuerdo con la TCAR}

Aunque en la actualidad el pronóstico de la sarcoidosis todavía se basa en la clasificación definida para la radiografía de tórax, existe mucha variabilidad interobservador, y se demostró la baja sensibilidad que tiene la radiografía para detectar adenomegalias y alteraciones parenquimatosas leves, por lo que se han realizado múltiples estudios en tomografía, demostrando que puede aportar información acerca de la reversibilidad de acuerdo con los hallazgos (Tabla 3), atribuyéndose los cambios reversibles a una inflamación activa (Figura 14); mientras que los irreversibles a fibrosis pulmonar (35).

Tabla 3. Reversibilidad de acuerdo con los hallazgos en TCAR

\begin{tabular}{|ll|}
\hline \multicolumn{1}{|c|}{ Cambios reversibles } & \multicolumn{1}{c|}{ Cambios irreversibles } \\
\hline Nódulos centrilobulillares & Panal de abejas \\
\hline Consolidación & Quistes \\
\hline Vidrio esmerilado & $\begin{array}{l}\text { Bulas y enfisema } \\
\text { paracicatrizal }\end{array}$ \\
\hline $\begin{array}{l}\text { Engrosamiento de septos } \\
\text { interlobulillares }\end{array}$ & Bronquiectasias de tracción \\
\hline & $\begin{array}{l}\text { Pérdida de volumen de los } \\
\text { lóbulos superiores }\end{array}$ \\
\hline
\end{tabular}

La extensión de los nódulos perilinfáticos se correlaciona con las pruebas de función pulmonar; así como también, los patrones de fibrosis se asocian con altera-
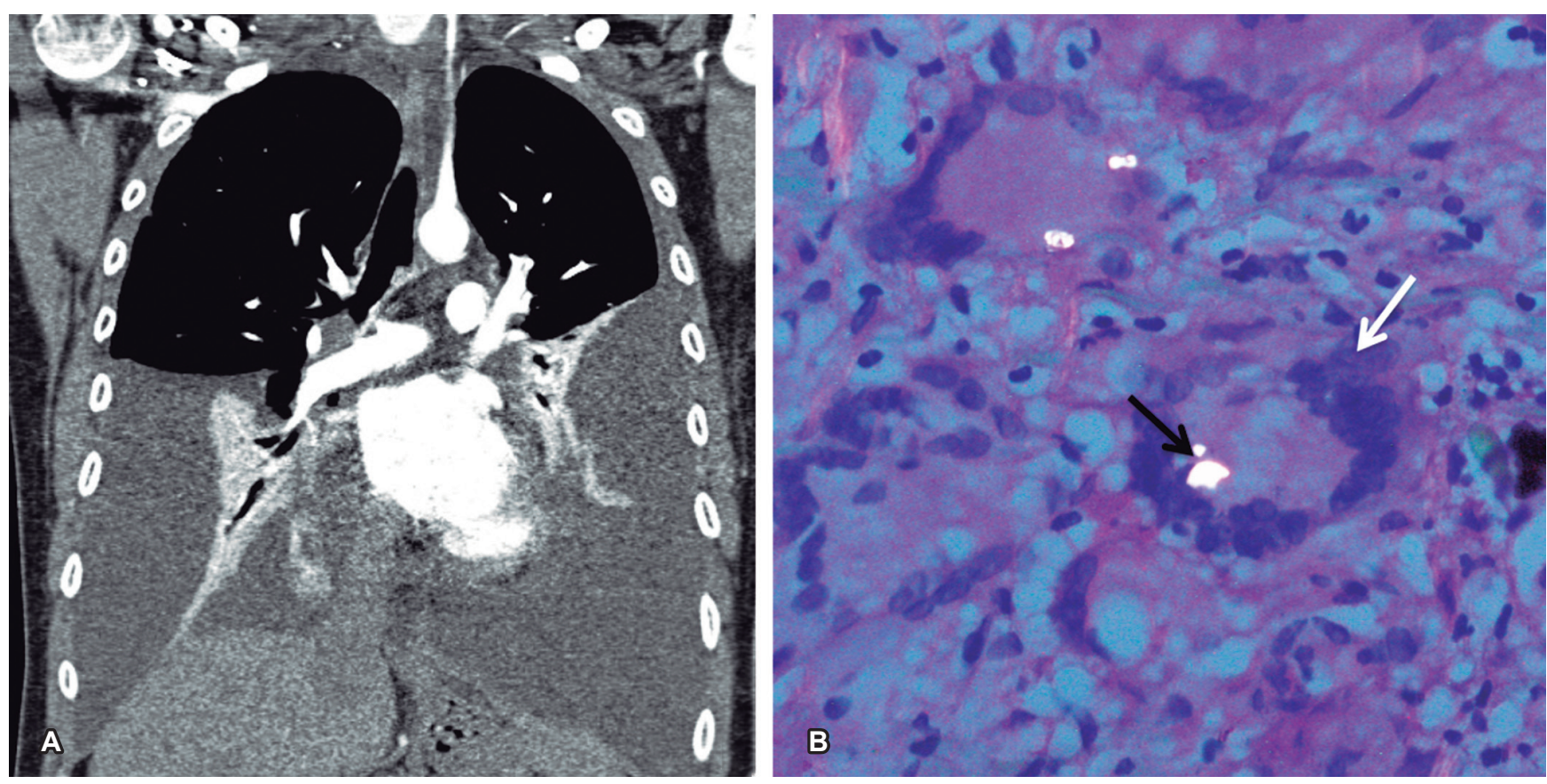

Figura 13. Paciente con sarcoidosis pleural. A. TCAR con evidencia de derrame pleural bilateral moderado, de características libres, con biopsia pleural. B. Con tinciones de hematoxilina/eosina se confirma la presencia de granulomas no caseificantes con células multinucleadas en su interior (flecha blanca), las cuales tienen cristales de oxalato de calcio dentro de las mismas (flecha negra), confirmando el diagnóstico de sarcoidosis pleural. 

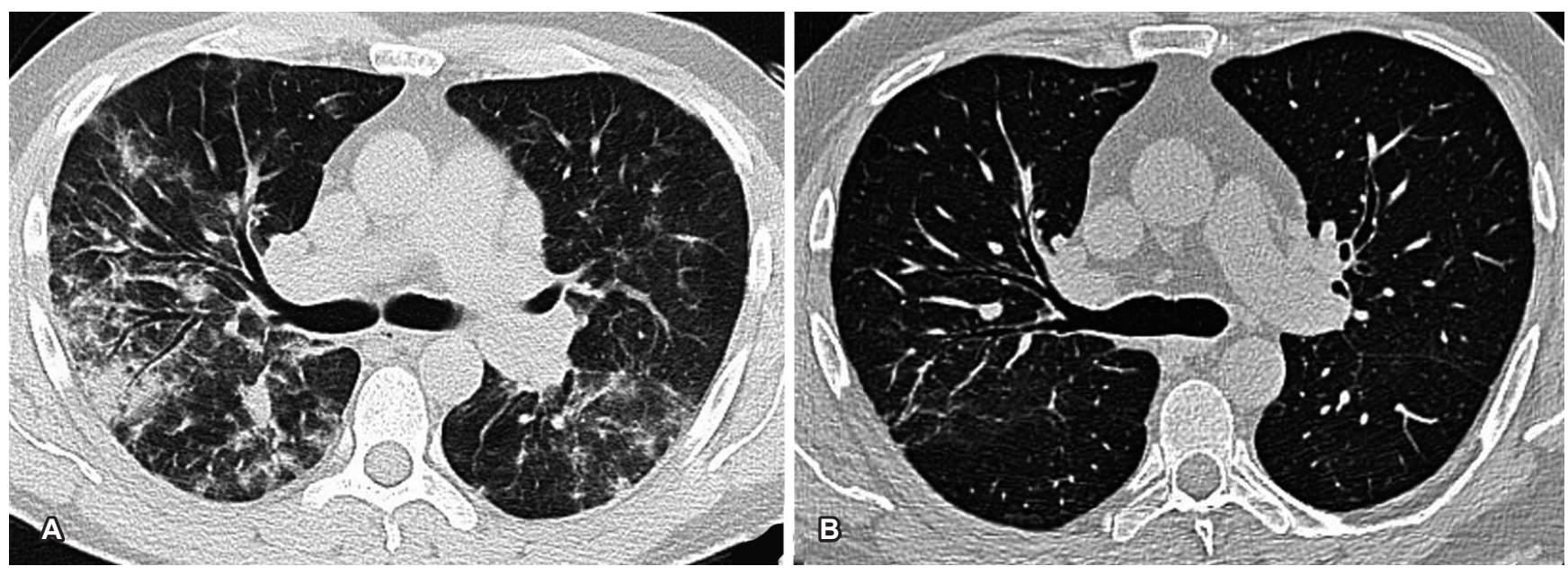

Figura 14. A. Paciente con sarcoidosis inicialmente manifestada como parches de consolidación y opacidades en vidrio esmerilado de distribución parahiliar y periférica. B. En la tomografía de control a los 2 años se observa una marcada disminución de las opacidades alveolares (hallazgo reversible).

ciones en las pruebas de función pulmonar; por ejemplo, la distorsión bronquial central se relaciona con un patrón obstructivo; mientras que la presencia de panal de abejas se asocia con un patrón restrictivo $(4,36)$.

\section{Sarcoidosis extrapulmonar}

El $30 \%$ de los pacientes tiene compromiso extrapulmonar, siendo los órganos más afectados el hígado (40\%-60\%) y bazo (50\%). En el hígado, la manifestación más frecuente es hepatomegalia y nódulos. Estos son hipoecoicos en ecografía, hipodensos en tomografía e hipointensos en todas las secuencias de resonancia magnética, con menor realce que el resto del parénquima hepático (Figura 15A) $(11,37)$. En el bazo, la sarcoidosis se manifiesta como esplenomegalia y nódulos, con igual comportamiento a los nódulos hepáticos en las diferentes modalidades de imágenes (Figura 15B) (11).

La sarcoidosis ósea es una manifestación tardía de la enfermedad y compromete, con mayor frecuencia, los huesos pequeños de las manos y pies. En la radiografía se manifiesta como lesiones líticas de aspecto quístico por osteólisis, con remodelación de la arquitectura cortical y trabecular, para dar el clásico patrón en encaje (Figura 15C) (11).
El compromiso cardíaco se documenta hasta en $25 \%$ de los pacientes (38). Se describe un amplio espectro de manifestaciones, como cardiomiopatías, arritmias ventriculares, lesiones valvulares, bloqueos cardíacos, falla cardíaca congestiva y muerte súbita. En los casos raros en que existe engrosamiento miocárdico, la resonancia magnética tiene buenos parámetros operacionales para detectar los granulomas, estos hallazgos incluyen hiperintensidad del miocardio afectado en imágenes potenciadas en T2, con realce tardío en secuencias contrastadas T1 eco gradiente con IR, engrosamiento y alteración focal en la contractilidad (Figura 16) (39).

\section{Pronóstico}

Generalmente el pronóstico es bueno, con remisión en $66 \%$ de los pacientes; sin embargo, aproximadamente $20 \%$ puede tener una evolución crónica y desarrollar fibrosis pulmonar (2). Los factores de mal pronóstico incluyen un estadio 2 o 3 de la enfermedad por imágenes al momento del diagnóstico, inicio después de los 40 años, raza negra, hipercalcemia, esplenomegalia, enfermedad ósea, uveítis crónica y lupus pernio.

Los factores de buen pronóstico son presentación con fiebre, poliarteritis, eritema nodoso y adenomega- 

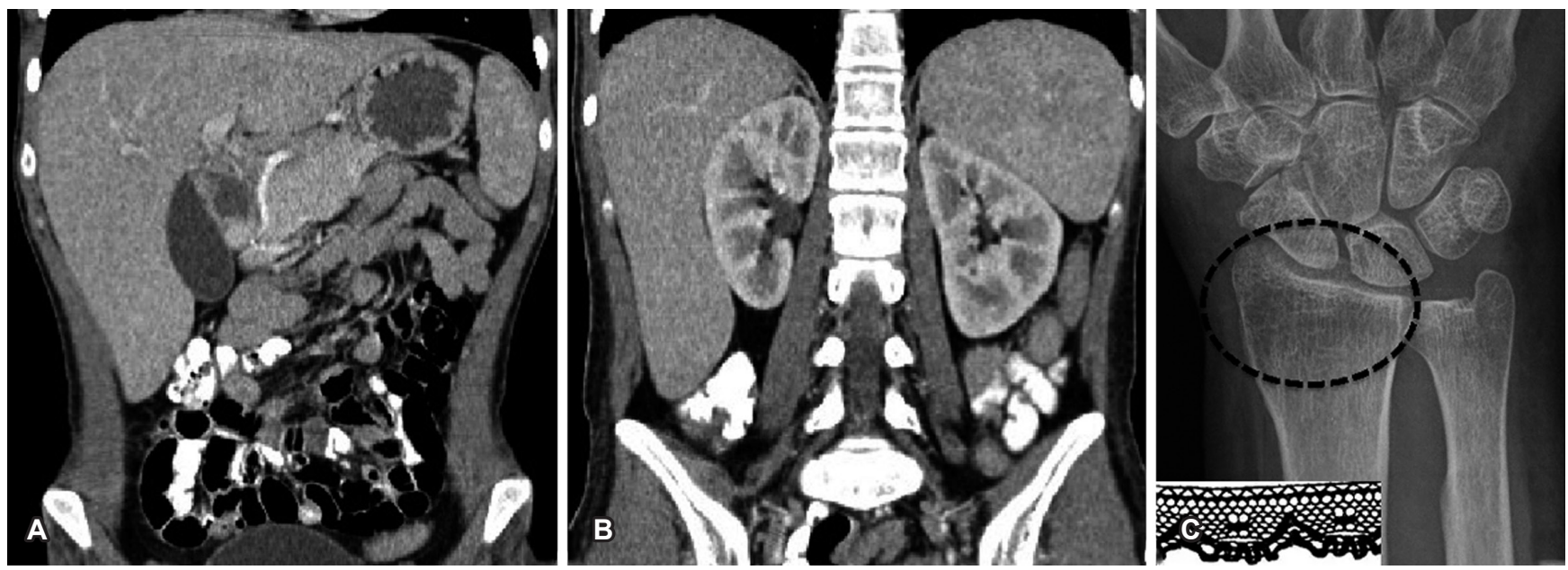

Figura 15. A y B. Reconstrucciones coronales de tomografía abdominal de una paciente con sarcoidosis abdominal, donde se identifica hepatoesplenomegalia. C. Radiografía de muñeca derecha con la clásica apariencia en encaje (circulo negro punteado) de la sarcoidosis ósea.
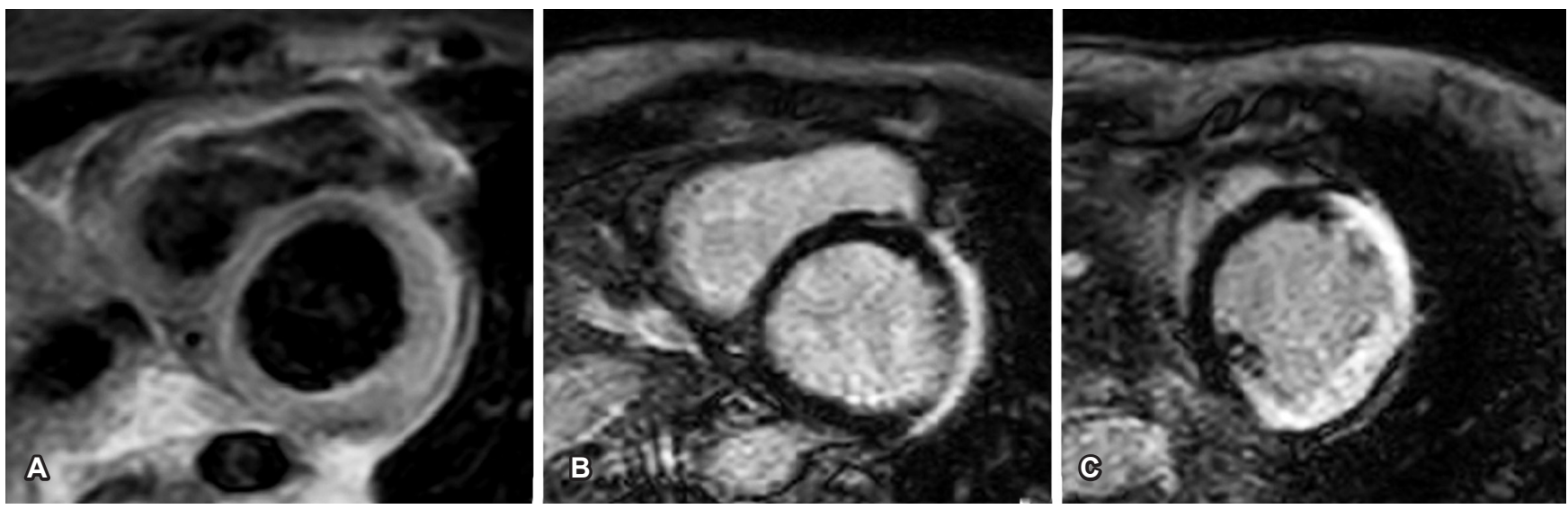

Figura 16. Resonancia magnética de corazón de un paciente con sarcoidosis (A), donde se identifica hiperintensidad en la pared lateral y anterior del ventrículo izquierdo en secuencias STIR, con realce tardío en la capa media del miocardio (B) y subepicárdico $(\mathbf{C})$ en las secuencias contrastadas T1 eco gradiente con IR.

lias hiliares bilaterales en conjunto, denominada síndrome de Lofgren.

\section{Conclusiones}

La sarcoidosis es una enfermedad crónica y multisistémica. Dentro de los órganos blanco, el afectado con mayor frecuencia es el pulmón, por lo que es importante revisar y conocer los diferentes patrones con los que se puede manifestar en las imágenes radiológicas, la cual es la primera herramienta de aproximación diagnóstica que tenemos disponible.

\section{Referencias}

1. Baughman RP, Teirstein AS, Judson MA, Rossman MD, Yeager $\mathrm{H}$, Bresnitz EA, et al. Clinical characteristics of patients in a case control study of sarcoidosis. Am J Respir Crit Care Med. 2001;164(10):1885-9. DOI: 10.1164/ajrccm.164.10.2104046.

2. Criado E, Sánchez M, Ramírez J, Arguis P, de Caralt TM, Perea RJ. Pulmonary sarcoidosis: typical and atypical manifestations at high-resolution CT with pathologic correlation. Radiographics. 2010;30(6):1567-86. DOI: 10.1148/ rg.306105512.

3. Baughman RP, Lower EE, Gibson K. Pulmonary manifestations of sarcoidosis. Presse Med. 2012;41:289-302. DOI: https://doi.org/10.1016/j.lpm.2012.03.019. 
4. Ors F, Gumus S, Aydogan M, Sari S, Verim S, Deniz O. HRCT findings of pulmonary sarcoidosis; relation to pulmonary function tests. Multidiscip Respir Med. 2013;8(1):8. DOI: 10.1186/2049-6958-8-8.

5. Müller-Quernheim J, Prasse A, Zissel G. Pathogenesis of sarcoidosis. Press Med. 2012;41(6):e275-87. DOI: https://doi. org/10.1016/j.lpm.2012.03.018.

6. Herráez I, López L. La sarcoidosis torácica. Radiología. 2011;53:434-48. DOI: 10.1016/j.rx.2011.03.010.

7. Balan A, Hoey ETD, Sheerin F, Lakkaraju A, Chowdhury FU. Multi-technique imaging of sarcoidosis. Clin Radiol. 2010;65:750-60. DOI: 10.1016/j.crad.2010.03.014.

8. Agarwal R, Aggarwal AN, Gupta D. Efficacy and safety of conventional TBNA in sarcoidosis: a systematic review and meta-analysis. Respir Care. 2013;58(4):683-93. DOI: 10.4187/respcare.02101.

9. de Boer S, Milne DG, Zeng I, Wilsher ML. Does CT scanning predict the likelihood of a positive transbronchial biopsy in sarcoidosis? Thorax. 2009;64(5):436-9. DOI: 10.1136/ thx.2008.105031.

10. Costabel U, Bonella F, Ohshimo S, Guzman J. Diagnostic modalities in sarcoidosis: BAL, EBUS, and PET. Semin Respir Crit Care Med. 2010;31(4):404-8. DOI: 10.1055/s-00301262207.

11. Vagal AS, Shipley R, Meyer CA. Radiological manifestations of sarcoidosis. Clin Dermatol. 2007;25(3):312-25. DOI: 10.1016/j.clindermatol.2007.03.009.

12. Statement on sarcoidosis. Joint Statement of the American Thoracic Society (ATS), the European Respiratory Society (ERS) and the World Association of Sarcoidosis and Other Granulomatous Disorders (WASOG) adopted by the ATS Board of Directors and by the ERS Executive Committee, February 1999. Am J Respir Crit Care Med. 1999;160(2):73655. DOI: 10.1164/ajrccm.160.2.ats4-99.

13. Scadding JG. Prognosis of intrathoracic sarcoidosis in England. Br Med J. 1961;2:1165-72. DOI: https://doi. org/10.1136/bmj.2.5261.1165.

14. DeRemee RA. The roentgenographic staging of sarcoidosis. Chest. 1983;83(1):128-33. DOI: https://doi.org/10.1378/ chest.83.1.128.

15. Little B. Sarcoidosis: overview of pulmonary manifestations and imaging. Semin Roentgenol. 2015;50(1):52-64. DOI: 10.1053/j.ro.2014.06.001.

16. Lynch JP. Computed tomographic scanning in sarcoidosis. Semin Respir Crit Care Med. 2003;24(4):393-418. DOI: 10.1055/s-2003-42375.

17. Kumazoe H, Matsunaga K, Nagata N, Komori M, Wakamatsu K, Kajiki A, et al. «Reversed halo sign» of highresolution computed tomography in pulmonary sarcoidosis. J Thorac Imaging. 2009;24(1):66-8. DOI: 10.1097/ RTI.0b013e318190476f.
18. Marchiori E, Zanetti G, Hochhegger B, Cameron RT, Loureiro K. Letters to the Editor. Radiographics. 2011;31:892.

19. Nakatsu M, Hatabu H, Morikawa K, Uematsu H, Ohno $\mathrm{Y}$, Nishimura K, et al. Large coalescent parenchymal nodules in pulmonary sarcoidosis: "sarcoid galaxy" sign. AJR Am J Roentgenol. 2002;178:1389-93. DOI: 10.2214/ ajr.178.6.1781389.

20. Harada T, Nabeshima K, Matsumoto T, Akagi T, Fujita M, Watanabe K. Histological findings of the computed tomography in pulmonary sarcoidosis. Eur Respir J. 2009;34:281-3. DOI

21. Marten K, Rummeny EJ, Engelke C. The CT halo: a new sign in active pulmonary sarcoidosis. Br J Radiol. 2004;77:1042-5. DOI: https://doi.org/10.1259/bjr/29049682.

22. Battesti JP, Saumon G, Valeyre D, Amouroux J, Pechnick B, Sandron D, et al. Pulmonary sarcoidosis with an alveolar radiographic pattern. Thorax. 1982;37:448-52. DOI: http:// dx.doi.org/10.1136/thx.37.6.448.

23. Nishimura $\mathrm{K}$, Itoh $\mathrm{H}$, Kitaichi $\mathrm{M}$, Nagai $\mathrm{S}$, Izumi T. Pulmonary sarcoidosis: correlation of CT and histopathologic findings. Radiology. 1993;189:105-9. DOI: https://doi.org/10.1148/radiology.189.1.8372178.

24. Hours S, Nunes H, Kambouchner M, Uzunhan Y, Brauner MW, Valeyre D, et al. Pulmonary cavitary sarcoidosis: clinico-radiologic characteristics and natural history of a rare form of sarcoidosis. Medicine (Baltimore). 2008;87(3):142-51. DOI: 10.1097/MD.0b013e3181775a73.

25. Ross JJ, Katz JD. Cryptococcal meningitis and sarcoidosis. Scand J Infect Dis. 2002;34(12):937-9. DOI

26. Damuth TE, Bower JS, Cho K, Dantzker DR. Major pulmonary artery stenosis causing pulmonary hypertension in sarcoidosis. Chest. 1980;78:888-91. DOI: https://doi.org/10.1378/ chest.78.6.888.

27. Hoffstein V, Ranganathan N, Mullen JB. Sarcoidosis simulating pulmonary veno-occlusive disease. Am Rev Respir Dis. 1986;134:809-11. DOI

28. Smith LJ, Lawrence JB, Katzenstein AA. Vascular sarcoidosis: a rare cause of pulmonary hypertension. Am J Med Sci. 1983(1);285:38-44. DOI: https://doi.org/10.1097/00000441198301000-00004.

29. Hawtin KE, Roddie ME, Mauri FA, Copley SJ. Pulmonary sarcoidosis: the 'Great Pretender'. Clin Radiol. 2010;65(8):64250. DOI: 10.1016/j.crad.2010.03.004.

30. Nunes H, Humbert M, Capron F, Brauner M, Sitbon O, Battesti JP, et al. Pulmonary hypertension associated with sarcoidosis: mechanisms, haemodynamics and prognosis. Thorax. 2006;61:68-74. DOI: 10.1136/thx.2005.042838.

31. Mendelson DS, Norton K, Cohen BA, Brown LK, Rabinowitz JG. Bronchial compression: an unusual manifestation of sarcoidosis. J Comput Assist Tomogr. 1983;7:892-4. DOI 
32. Hennebicque AS, Nunes H, Brillet PY, Moulahi H, Valeyre D, Brauner MW. CT findings in severe thoracic sarcoidosis. Eur Radiol. 2005;15(1):23-30. DOI: https://doi.org/10.1007/ s00330-004-2480-4.

33. Viskum K, Vestbo J. Vital prognosis in intrathoracic sarcoidosis with special reference to pulmonary function and radiological stage. Eur Respir J. 1993;6:349-53. DOI

34. Froudarakis ME, Bouros D, Voloudaki A, Papiris S, Kottakis Y, Constantopoulos SH, et al. Pneumothorax as a first manifestation of sarcoidosis. Chest. 1997;112(1):278-80. DOI: https://doi.org/10.1378/chest.112.1.278.

35. Wells A. High resolution computed tomography in sarcoidosis: a clinical perspective. Sarcoidosis Vasc Diffuse Lung Dis. 1998;15(2):140-6. DOI

36. Abehsera M, Valeyre D, Grenier P, Jaillet H, Battesti JP, Brauner MW. Sarcoidosis with pulmonary fibrosis: CT patterns and correlation with pulmonary function. Am J Roentgenol. 2000;174:1751-7. DOI: 10.2214/ajr.174.6.1741751.

37. Gezer NS, Başara I, Altay C, Harman M, Rocher L, Karabulut N, et al. Abdominal sarcoidosis: cross-sectional imaging findings. Diagnostic Interv Radiol. 2015;21:111-7. DOI: 10.5152/dir.2014.14210.

38. Ratner SJ, Fenoglio JJ, Ursell PC. Utility of endomyocardial biopsy in the diagnosis of cardiac sarcoidosis. Chest. 1986;90:528-33. DOI: https://doi.org/10.1378/chest.90.4.528.

39. Vignaux O, Dhote R, Duboc D, Blanche P, Dusser D, Weber $\mathrm{S}$, et al. Clinical significance of myocardial magnetic resonance abnormalities in patients with sarcoidosis: a 1-year follow-up study. Chest. 2002;122(6):1895-901. DOI: https:// doi.org/10.1378/chest.122.6.1895. 